Arab World English Journal (AWEJ) Volume 12. Number4 December 2021

DOI: https://dx.doi.org/10.24093/awej/vol12no4.12

Pp. $167-177$

\title{
Effects of Language Variety and Word Availability in Commercial Advertisements on Listener's Lexical Recall
}

\author{
Munerah Algernas \\ Department of Linguistics \& Translation Studies \\ College of Languages \& Translation \\ King Saud University, Saudi Arabia \\ Corresponding Author: malgernas@gmail.com
}

\author{
Yahya Aldholmi \\ Department of Linguistics \& Translation Studies \\ College of Languages \& Translation \\ King Saud University, Saudi Arabia
}

Received: 9/15/2021

Accepted: $10 / 20 / 2021$

Published: 12/15/2021

\section{Abstract}

Commercial advertisements in Arabic-speaking regions tend to alternate between dialectal Arabic and Modern Standard Arabic, but it is not yet clear whether language variety has any impact on listener's lexical recall. Insight into this issue should help enterprises design their commercial advertisements in a linguistically intelligent manner. This study addresses two questions: 1) How does language variety (dialectal vs. standard) affect listener's lexical recall in commercial advertisements? 2) Do listeners recall words that have appeared in dialectal advertisements better than those that did not appear in advertisements using the same variety? Fifteen Saudi participants responded to a forced-choice memory test with 24 yes-no questions (3 per advertisement) asking participants to report whether they heard a specific key word in eight advertisements that utilized different language varieties. The findings show that Arabic speakers tend to perceive both Modern Standard Arabic and dialectal Arabic in commercial advertisements similarly, but tend to recall the presence of a key word in an advertisement better than its absence. Future research may increase the sample size and examine more Arabic varieties.

Keywords: commercial advertisements, dialectal Arabic, memory, Modern Standard Arabic, language variety, lexical recall

Cite as: Algernas, M., \& Aldholmi, Y. (2021). Effects of Language Variety and Word Availability in Commercial Advertisements on Listener's Lexical Recall. Arab World English Journal, 12 (4) 167-177. DOI: https://dx.doi.org/10.24093/awej/vol12no4.12 
Arab World English Journal (AWEJ) Volume 12. Number 4. December 2021

Effects of Language Variety and Word Availability in Commercial Advertisements

Algernas \& Aldholmi

\section{Introduction}

Many enterprises use commercial advertising with the aim of selling certain products or persuading consumers to use particular services in a competitive and dynamic market (e.g., Erickson 1985; Korgaonkar, Karson, \& Akaah 1997; Yang, Ahn, \& Han, 2013). Differences in the language varieties and speech characteristics used in such advertisements are expected to have an influence on cognitive processes and memory recall. Voices in advertisements are usually human, and humans have different vocal tracts that shape their production. Yet, people are capable of perceiving and comprehending speech produced by different speakers through a process of speech normalization (Johnson, 2005), which filters speech to allow listeners access to a representation in the mental lexicon (see e.g., Krulee, Tondo, \& Wightman 1983; Johnson, 2005; Johnson \& Sjerps, 2021). Researchers continue to study the impact of additional factors such as speech rate (e.g., Rodero, 2019), gender (e.g., Rodero, Larrea, \& Vázquez, 2013), pitch (e.g., Rodero, Potter, \& Prieto, 2017), and accent/language variety (e.g., Birch \& McPhail, 1997; Lalwani, Lwin, \& Li, 2005) on cognitive processing in general, and cognitive processing of commercial advertising in particular. Cognitive processes are tied to an individual's capacity to store, comprehend, and recall information. An essential component of cognitive processing is memory recall, for example, lexical recall. Episodic theory suggests that perceptual details are kept in memory and are fundamental to later speech recognition (see e.g., Goldinger, 1998).

The impact of language variety on lexical recall in commercial advertisements has been examined in other languages such as English and Chinese, but to the best of our knowledge there is no empirical study (other than our conference presentation, Algernas \& Aldholmi, 2021, May) that has compared the impact of the use of dialectal Arabic (DA) (specifically, Najdi Arabic) vs. Modern Standard Arabic (MSA) on listener's lexical recall in commercial advertisements. Put differently, there is a lack of guidance from the Arabic linguistic literature on the importance of language variety selection in commercial advertisements. Considering the diglossic status of Arabic in Saudi Arabia where people are exposed to DA more than MSA in daily conversations, we would expect that MSA advertisements should have a different impact than DA advertisements on an audience's recall of content presented to them, and that the (un)availability of a key word in the advertisement should be different in the two varieties. This potential impact is critical for enterprises designing a product advertisement, because if a variety is more likely to result in better recall of brand name and information, then we would expect designers to make choices to prefer such a variety. Hence, the outcome of this study (as well as future studies) should aid businesses in determining the variety of language they should utilize in their commercial advertisements.

We pose two research questions with related hypotheses, as stated below.

Research question 1: How does language variety (DA vs. MSA) affect listener's lexical recall of commercial advertisements?

Hypothesis 1: listeners will remember words from advertisements that use DA better than words from advertisements that use MSA since studies have shown that listeners have better recall of a familiar accent over time (Bottriell \& Johnson, 1985).

Research question 2: Does the (un)availability of a key DA vs. MSA word in the advertisement have any impact on a listener's lexical recall? 
Arab World English Journal (AWEJ) Volume 12. Number 4. December 2021

Effects of Language Variety and Word Availability in Commercial Advertisements

Algernas \& Aldholmi

Hypothesis 2: listeners will recall words that have appeared in the DA advertisements better than those that did not appear in advertisements using the same variety, since previous studies have shown that standard varieties have a negative impact on memory recall (Morales et al., 2012).

\section{Literature review}

Research has identified several factors that influence memory recall of product name and other relevant information in advertisements. One factor that may be predicted to affect the recall process is speaker gender. Leung and Kee (1999) examined the impact of male voiceover on the recall of brand names and found that using male "celebrity voiceover in TV commercials is effective for facilitating recall and comprehension on information associated with the advertisement" (p. 89). Two important facets of their findings must be noted here. First, this facilitatory effect on recall is only effective within a short lag; that is, the impact of male celebrity voiceover in advertisements on recall emerges only when it is measured right after the participants have been exposed to the advertisements. Second, they found no significant difference between males and female participants' ability to recall brand names. Rodero et al. (2013) also explored how the gender of voices can contribute to the effectiveness and recall of the messages from radio advertisements in Spain. Due to some gender-related assumptions that favor male voices in Spain, a male voice was expected to be more persuasive and to attract attention more than a female voice in a commercial advertisement. However, their findings did not support the effectiveness of a male voice for level of recall of an advertised product.

Another factor that is related to the gender of a voice is pitch. Rodero et al. (2017) compared the number of correct words recalled across four intonation patterns and found that commercial messages with pitch variations, compared to those with a homogenous pitch, have a positive impact on recall and memory. A third factor that has been researched in detail as having an effect on a listener's memory of advertisements is speech rate. Rodero (2019) explored the effect of using three different speech rates $(160,180$, and 200 words per minute) in advertisements on short-term memory. He concluded that using a moderate speech rate results in the highest level of correct lexical recall, while fast and low speech rates have low levels of lexical recall. Some other studies have attempted to test these two factors simultaneously. For instance, Chattopadhyay, Dahl, Ritchie, and Shahin (2003) examined whether pitch or/and speech rate (among other characteristics) enhance or reduce a listener's response to advertisements. Specifically, among other dependent variables, the participants had to recall information about the brand mentioned in the advertisements. The results show that a low-pitched voice is preferred when the announcer is male, that accelerated speech rate could be an important element for advertising effectiveness, and that the two factors in question exhibit interaction effects.

Especially in international contexts, another important component of speech in commercial advertising is language variety or accent (e.g., Domzal, Hunt, \& Kernan, 1995; Hornikx \& van Meurs, 2020). This factor has been well studied in English (e.g., Birch \& McPhail, 1997; Lalwani et al., 2005; Reinares-Lara, Martín-Santana \& Muela-Molina, 2016). For instance, Lalwani et al. (2005) examined the effect of Standard English vs. Singaporean English on consumers' attitudes towards advertisements. The authors distinguished between products of domestic origin and products of foreign origin and the results of their study confirmed the impact of language variety (as well as product origin) on the audience's attitudes towards 
Arab World English Journal (AWEJ) Volume 12. Number 4. December 2021

Effects of Language Variety and Word Availability in Commercial Advertisements

Algernas \& Aldholmi

advertisements. A later study (Morales, Scott, \& Yorkston, 2012) examined the impact of accented English (American) vs. Standard English (British) on both consumers' recall for products and services as well as their evaluations of them. Interestingly, the results show that Standard English did not positively impact the listeners' memory but rather lowered brand recall. Domzal (1995) found that nonnative words "have the capability of enabling advertisements to be noticed more, processed deeper, and remembered more readily than equivalent advertisements using no foreign words" (p. 100).

Although this type of research has covered a variety of languages such as Swahili (Mutonya, 2008), Mandarin (Liu, Wen, Wei, \& Zhao, 2013), and German (Hendriks, van Meurs, \& Behnke, 2019), much of the literature is devoted to different varieties of English in particular, including British, American, Australian, Singaporean, Indian, and Asian Englishes, particularly in terms of Standard vs. Nonstandard (accented, foreign, or colloquial) English. Nevertheless, the differences between some of these varieties (such as American vs. British or British vs. Australian) are not as substantial as the differences between MSA and DA. Only a few studies have tested the impact of Arabic varieties (e.g., Gully, 1996) or English vs. Arabic vs. Arabinglish (e.g., Nickerson \& Camiciottoli, 2013; Sobh, Singh, Chun, \& Benmamoun, 2018) on listeners' perception of, reactions towards, and recall of advertisements or the messages they deliver. However, most of the existing studies on Arabic either focus on written/print advertisements, examine foreign vs. native language, use theoretical discourse-based approaches, and/or took a non-linguistic perspective.

\section{Methods \\ Stimuli}

The stimuli used in the present study consisted of eight carefully selected auditory MSA and DA commercial advertisements. The number of advertisements is less than that used in previous studies such as Rodero et al. (2017) and Rodero (2019) which used 16 and 12, respectively. However, the number of advertisements per condition is the same as in these studies. The present study compares only two conditions, MSA vs. DA, with four advertisements per condition, while Rodero et al. (2017) have four conditions (four intonation levels, four advertisements per condition), and Rodero (2019) has three conditions (three speech rates, four advertisements per condition). Stimuli selection was based on a strict criterion that included only the advertisements that differed in language variety but were similar with respect to advertisement length, narrator gender, number of narrators, speech rate, pitch, product familiarity, and presentation modality.

All advertisements were similar in length (MSA $M=58.25, S D=2.2$, DA $M=54.5, S D=4.0$, MSA \& DA $M=56.37, S D=3.66$ ), and any advertisement that did not fill in that range was excluded from the stimuli. This length is almost double the length reported in Rodero et al. (2017), but as the task is less challenging in the current study (lexical recall in which the participants were only asked to judge if they heard a lexical item or not) than the one in their study (word recall, in which the participants were asked to type as many recalled words as possible). Second, all of the advertisements in both varieties were produced in a male voice for the sake of consistency and to avoid gender effects. Third, only one talker appeared in each advertisement; none involved multiple talkers. Fourth, speech rate was controlled with all advertisements having almost the same range of words (MSA $M=99.25, S D=7.9$, DA $M=105$, $S D=13.0$, MSA \& DA $M=102.375, S D=10.82)$ and hence similar speech rate (MSA $M=1.7$, 
$S D=3.5$, DA $M=1.9, S D=3.2$, MSA \& DA $M=1.81, S D=3.0$ words per second). Fifth, pitch is also taken into consideration in the present study. At the discretion of the experimenters, pitch featured high and low variations in all advertisements. Sixth, all advertisements were for products and services that our participants would have been rarely exposed to as an attempt to prevent any prior familiarity effects. The participants were asked to report if they had previously heard any of the advertisements, and all responses were negative (i.e., no participant had heard any of the advertisements). Note that the advertisements were originally in visual form, but were converted and presented to participants in auditory form in order to avoid any confounding effect from the visuals and to allow participants to focus only on the speech presented to them. This also makes our design more similar to the studies reviewed above that examined various language aspects in audio commercials.

\section{Participants}

A convenience sampling was used to recruit the participants. The researchers announced the study to graduate students in the Department of Linguistics at King Saud University and called for participation in an online experiment. The recruitment script stated the target sample (native speakers of Najdi Arabic who have no hearing issues) and provided some basic information about the study. Fifteen participants $(n=15)$ volunteered to participate in this study. All participants were native females who speak both MSA and the Najdi dialect of Arabic. It was necessary to use only one gender type to avoid any gender effect between the participants and the announcers/talkers in the advertisements. Participants were asked to report demographic information including their education, age, and speech- and hearing-related issues. All participants had a tertiary level of education, and participant age varies from 19 to 28 ( $M=22.4)$. None of the participants reported any hearing impairments.

\section{Task, Procedures, and Instruments}

A forced-choice memory test in the form of a yes-no question was implemented. Each participant was asked three questions per advertisement (making up a total of 24 questions) about whether she had heard a certain word in the presented advertisements or not. The three questions were of three types: one question was about a key word that did appear in the advertisement (available), another question was about a word that did not appear in the advertisement (unavailable), and one question was a distracter to reduce the likelihood that participants discover the goals of the study. The key words in the questions were varied in that they appeared in different positions (beginning, middle, and end) in the advertisements, and were semantically related to the theme of the advertisement. The advertisements were presented in audio format, not in their original visual form, as explained above.

Due to the global COVID-19 pandemic during which this study was undertaken, the experiment was conducted remotely over a period of three days. Each participant was asked to join a Zoom meeting individually and share her computer screen so that the experimenters could monitor the experiment's execution. In each meeting, the task and its procedure were explained to the participant. The order of the advertisements within and across language varieties (MSA vs. DA) and of questions (available vs. unavailable vs. distractor) was completely counterbalanced, and different participants encountered different orders. Each advertisement was played only once, and participants were allowed 30 seconds to provide an answer for each question, 
following Rodero et al. (2017). The average length for each meeting was approximately twenty minutes.

\section{Findings}

Each participant answered 24 questions to provide a total of 360 responses. Note that a third of the trials (120) were distractors and hence their responses were excluded. This leaves a remainder of 240 responses for analysis. As shown in Figure 1, the accuracy rate (proportion of correct answers) was $83.33 \%$ (100 out of 120 ) and $82.5 \%$ (99 out of 120) for DA and MSA advertisements, respectively. A binomial repeated-measure logistic regression with language variety and word (un)availability as two predictor variables and responses as a predicted variable was performed. The logistic regression model revealed no statistically significant effect of language variety, [Wald $\chi 2(1)=.088, \mathrm{p}=.767,95 \% \mathrm{CI}(-.536-1.116)]$.

MSA vs. DA

MSA

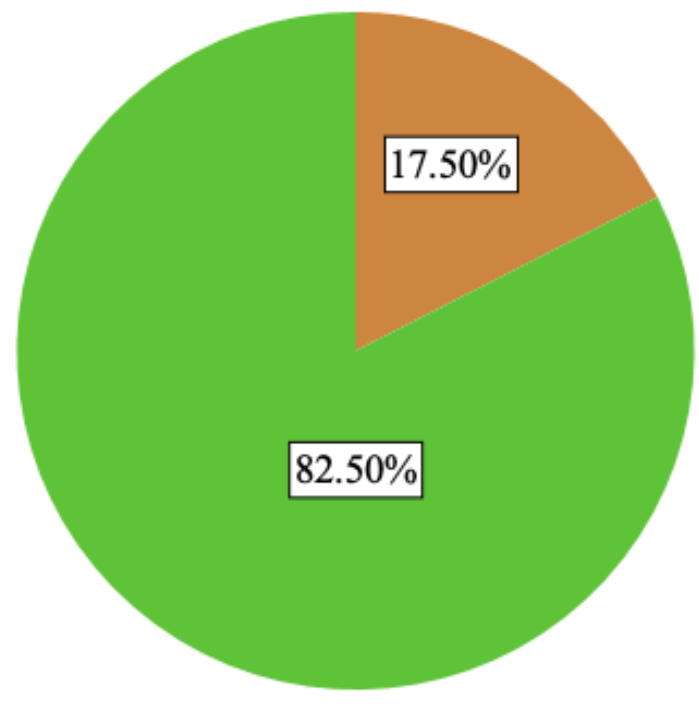

DA

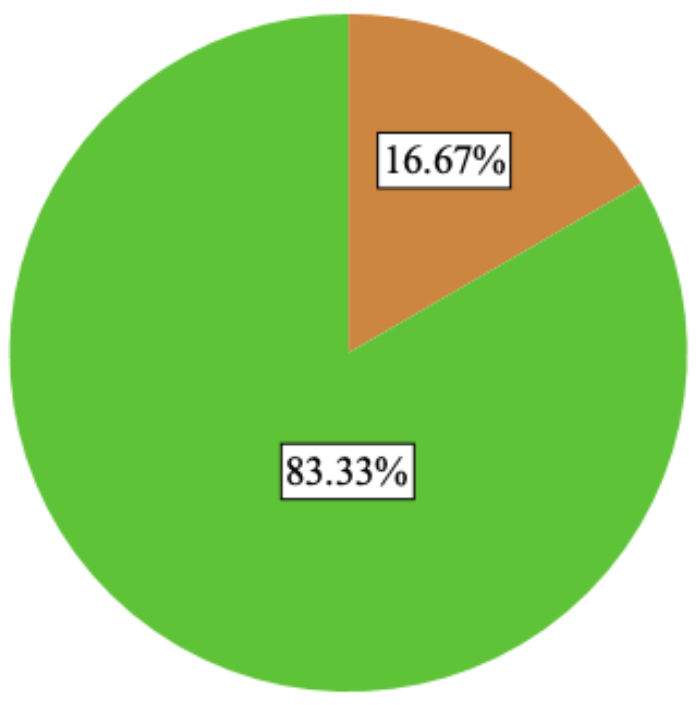

Figure 1. Accuracy rate broken down by language variety

As can be seen in Figure 2 below, the accuracy rate was higher for the available condition $(86.67 \%, 104$ out of 120$)$ than for the unavailable condition $(79.17 \%, 95$ out of 120$)$. The binomial repeated-measure logistic regression revealed that word availability was a statistically significant explanatory factor in the participants responses. [Wald $\chi^{2}(1)=.4 .251, \mathrm{p}=.039,95 \%$ CI (-.979-.283)]. 


\section{Available vs, Unavailable}

Available

Unavailable

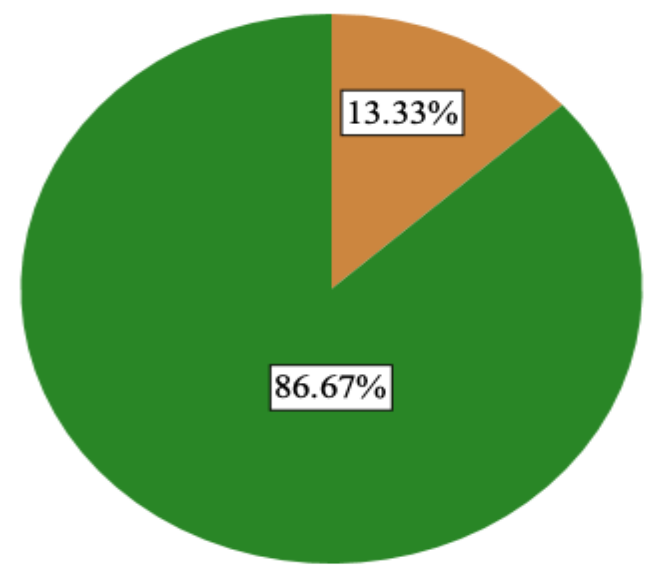

\section{Responses}

Incorrect

Correct

\section{Figure 2. Accuracy rate broken down by word (un)availability}

Looking into details, the accuracy rate for the available condition was $85 \%$ in MSA and $88.33 \%$ in DA, whereas the accuracy rate for the unavailable condition was $80 \%$ in MSA and $78.33 \%$ in DA. However, the logistic regression model revealed no evidence for statistically significant interactions between the two variables, [Wald $\chi^{2}(1)=.598, \mathrm{p}=.439,95 \%$ CI (-1.381 -.599)].

\section{Available vs. Unavailable}

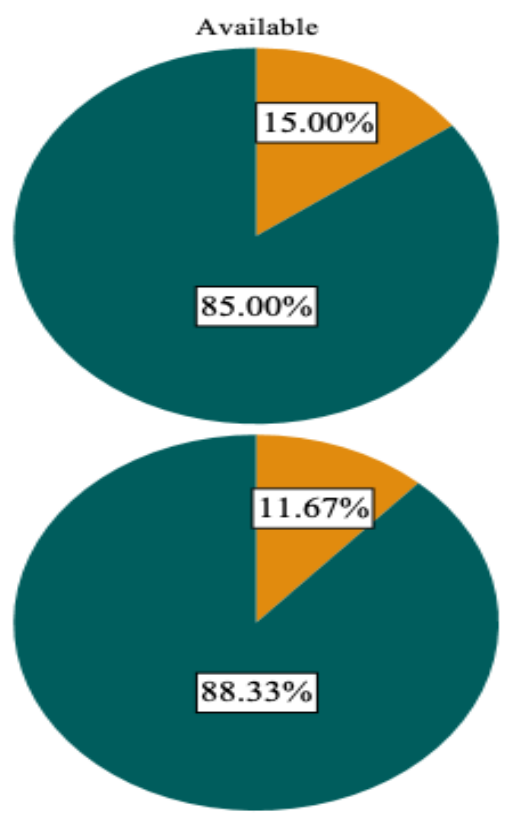

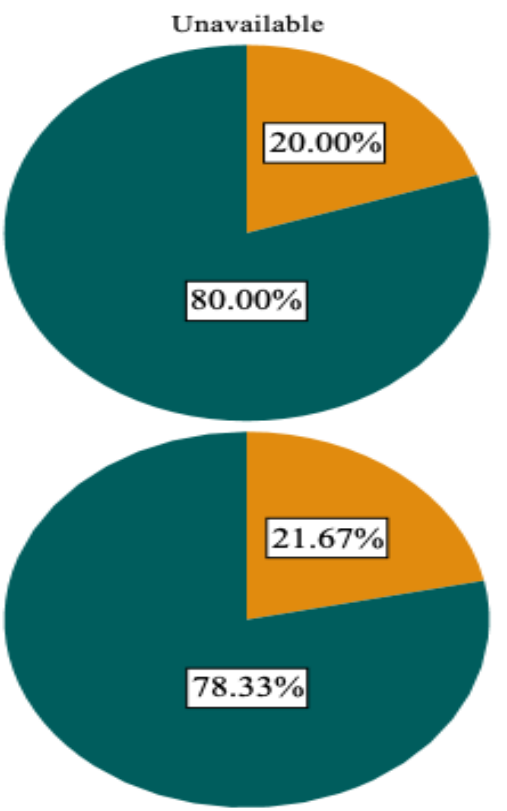

\section{Responses}

Incorrect

Correct

Figure 3. Accuracy rate broken down by language variety and word (un)availability Discussion

Our first question asks whether Arabic speakers better recall advertisements that utilize either one of the two varieties under investigation, namely MSA and DA. The first set of the findings 
shows that language variety, as indicated by the statistical test output, is not a factor affecting lexical recall; hence, our initial hypothesis that people usually remember words from DA advertisements better than they remember words from MSA advertisements is disconfirmed. Although the present work is similar to previous studies discussed above, there are notable theoretical and methodological differences that should be pointed out.

First, previous studies focused on the impact of foreign vs. native language (rather than standard vs. nonstandard variety) on recall and found that nonnative words result in better recall. For example, Domzal et al. (1995) showed that advertisements that use foreign words are more notable and memorable than those that do not use foreign words. Petrof (1990) also supports this claim, demonstrating that American participants better recalled messages in French advertisements than in English advertisements (as cited in Hornikx \& van Meurs, 2020). Similar results were found when Korean consumers were presented with English advertisements (e.g., Ahn \& Ferle, 2008). One would expect that a similar effect would appear for a standard variety presented to speakers of a dialectal variety, especially in a diglossic situation in which the differences between the standard variety and the dialectal variety are substantial, as is the case in Arabic. However, this did not emerge in the present findings, probably because the status of MSA is not comparable to the status of a foreign language (regardless of the position one takes with respect to whether MSA is a native language for DA speakers). Nevertheless, we should note that while some studies support the privilege of a foreign language in advertisements, other studies have found that "the complexity of a foreign language hinders recall because an utterance in a foreign language is less strongly linked to the underlying concepts in the mind" (Hornikx \& van Meurs, 2020, p. 86). Neither of these two differences appeared in the findings on MSA vs. DA advertisements. Hence, an alternative explanation is considered below.

Studies that focus on standard vs. nonstandard varieties seem to be more relevant and comparable to the current work. Morales et al. (2012) hypothesized that although people perceive standard accent as being more correct and prestigious, people devote more attention to the accent itself rather than to the content of a message, consequently having a negative impact on recall. Our findings do not support a similar hypothesis. There is a notable methodological difference, specifically in the task used, between Morales's et al. (2012) study and the present study. Several previous studies, including Morales et al. (2012), ask participants to recall the specific brand name or the copy body message that appeared in a presented advertisement (e.g., Dozmal et al., 1995; Luna \& Peracchio, 2001). In the present work, the participants were asked to recall a key word that either appeared or did not appear in the advertisement. This task may have reduced the impact of language variety, because it is not easy to maintain the distinction between a MSA lexical item and a DA lexical item.

The second question asked whether the (un)availability of a key DA vs. MSA word in the advertisement may have any impact on a listener's lexical recall. Our second hypothesis was partially confirmed. The participants were better able to recall the words that appeared in the advertisements than those that did not appear. However, our distinction between word (un)availability in MSA vs. DA was not borne out. Recall of lexical items that were available in advertisements was better than that of lexical items that were unavailable in advertisements regardless of language variety. However, we believe that when a word that had been presented to the participants appeared again in the question posed to the participants, participants recognized 
the items and hence were less confused than when they were not exposed to the items. This distinction between recall and recognition has been a topic of debate in the field of memory in general and in advertising studies more specifically (see e.g., Du Plessis, 1994, for an overview). However, that is not the focus of the current study.

\section{Conclusion}

To conclude, this study has attempted to examine whether Arabic speakers better recall words from advertisements that utilize either one of two varieties, MSA vs. DA, and whether the (un)availability of a key DA vs. MSA word in the advertisement may have any impact on a listener's lexical recall. The findings show that Arabic speakers tend to perceive both MSA and DA in commercial advertisements similarly and that the variety used in advertisements does not seem to have any impact on their recall of the advertisement content. Moreover, the results show that Arabic speakers recall the availability of a key word in an advertisement better than its absence, regardless of whether the word is MSA or DA. This study provides preliminary findings, despite some limitations. First, the data collected in this study was limited to only eight advertisements and sixteen trials per participant. Potentially, with more advertisements, a difference between MSA and DA with respect to lexical recall may emerge. Second, the sample size was limited and constrained by the global COVID-19 pandemic during which recruiting participants was an especially hard task. These two limitations could have affected our statistical analysis and findings and therefore conducting this study at a larger scale is highly recommended.

\section{About the authors}

Munerah Algernas a graduand MA student of linguistics in the Department of Linguistics and Translation studies, King Saud University. She holds a bachelor's degree in English language and literature from Prince Sattam bin Abdulaziz University. Her chief research interests are both theoretical and experimental linguistics, including sociolinguistics and psycholinguistics. ORCID ID: https://orcid.org/0000-0001-9392-631X.

Yahya Aldholmi, PhD. an assistant professor in the Department of Linguistics and Translation Studies, King Saud University. His primary research interest is "experimental linguistics", with a focus on speech perception, and his secondary interests are theoretical linguistics (mainly phonology) and applied linguistics (mainly language acquisition and forensic phonetics). Other than linguistics degrees, he also holds an MS in computer science and an MS in educational technology, which stretch his interests outside the linguistics domain. ORCID ID: https://orcid.org/0000-0003-2373-1335

\section{References}

Ahn, J., \& Ferle, C. L. (2008). Enhancing recall and recognition for brand names and body copy: A mixed-language approach. Journal of Advertising, 37(3), 107-117. https://doi.org/10.2753/JOA0091-3367370308

Algernas, M. \& Aldholmi, Y. (2021, May) The effects of language variety and word availability in commercial advertisements on listener's lexical recall. $22^{\text {th }}$ International Meeting for Young Linguists (abstract \& presentation), Olomouc, Czech Republic. 17-18 ${ }^{\text {th }}$ May, 2021. http://mladilingviste.upol.cz/wp-content/uploads/2021/05/Book-of-2021-1.pdf 
Arab World English Journal (AWEJ) Volume 12. Number 4. December 2021

Effects of Language Variety and Word Availability in Commercial Advertisements

Algernas \& Aldholmi

Birch, D., \& McPhail, J. (1997). The Impact of Accent in International Television Advertising. Global Business Languages, 2, 91-105.

Bottriell, W. J., \& Johnson, F. N. (1985). Effects of a speaker's accent on the listener's memory for verbal material: I. Immediate recall. IRCS Medical Science: Psychology \& Psychiatry, 13(11-12), 1046-1047.

Chattopadhyay, A., Dahl, D. W., Ritchie, R. J., \& Shahin, K. N. (2003). Hearing voices: The impact of announcer speech characteristics on consumer response to broadcast advertising. Journal of Consumer Psychology, 13(3), 198-204. https://doi.org/10.1207/S15327663JCP1303_02

Domzal, T. J., Hunt, J. M., \& Kernan, J. B. (1995). Achtung! The information processing of foreign words in advertising. International Journal of Advertising, 14(2), 95-114. https://doi.org/10.1080/02650487.1995.11104603

Du Plessis, E. (1994). Recognition versus recall. Journal of Advertising Research, 34(3), 75-92.

Erickson, G. M. (1985). A model of advertising competition. Journal of Marketing Research, 22(3), 297-304. https://doi.org/10.1177/002224378502200305

Goldinger, S. D. (1998). Echoes of echoes? An episodic theory of lexical access. Psychological Review, 105(2),--251-279. doi:10.1037/0033-295x.105.2.251

Gully, A. (1996). The discourse of Arabic advertising: Preliminary investigations. Journal of Arabic and Islamic studies, 1-49. https://doi.org/10.5617/jais.4544

Hendriks, B., van Meurs, F., \& Behnke, G. (2019). The effect of different degrees of regional accentedness in radio commercials: An experiment with German consumers. Journal of International Consumer Marketing, 31(4),302-316. https://doi.org/10.1080/08961530.2018.1544530

Hornikx, J., \& van Meurs, F. (2020). Foreign languages in advertising: Linguistic and marketing perspectives. Gewerbestrasse: Springer Nature. https://doi.org/10.1007/978-3030-31691-4

Johnson, K. (2005). Speaker normalization in speech perception. In D. B. Pisoni \& R. E. Remez (Eds.), Blackwell handbooks in linguistics. The handbook of speech perception (363389). Blackwell Publishing. https://doi.org/10.1002/9780470757024.ch15

Johnson, K., \& Sjerps, M. J. (2021). Speaker normalization in speech perception. The Handbook of Speech Perception, 145-176. https://doi.org/10.1002/9781119184096.ch6

Korgaonkar, P. K., Karson, E. J., \& Akaah, I. (1997). Direct marketing advertising: The assents, the dissents, and the ambivalents. Journal of Advertising Research, 37(5)-41-56.

Krulee, G., Tondo, D., \& Wightman, F. (1983). Speech perception as a multilevel processing system. Journal of Psycholinguistic Research, 12:531-554.

Lalwani, A. K., Lwin, M., \& Li, K. L. (2005). Consumer responses to English accent variations in advertising. Journal of Global Marketing, 18(3-4), 143-165.

Leung, L., \& Kee, O. K. (1999). The effects of male celebrity voice-over and gender on product brand name recall, comprehension, and purchase intention. Atlantic Journal of Communication, 7(1), 81-92. https://doi.org/10.1080/15456879909367356

Liu, S., Wen, X., Wei, L., \& Zhao, W. (2013). Advertising persuasion in China: using Mandarin or Cantonese? Journal of Business research, 66(12)-2383-2389. https://doi.org/10.1016/j.jbusres.2013.05.024

Luna, D., \& Peracchio, L. A. (2001). Moderators of language effects in advertising to bilinguals: A psycholinguistic approach. Journal of Consumer Research, 28(2), 284-295. https://doi.org/10.1086/322903 
Morales, A. C., Scott, M. L., \& Yorkston, E. A. (2012). The role of accent standardness in message preference and recall. Journal of Advertising, 41(1), -33-46. https://doi.org/10.2753/JOA0091-3367410103

Mutonya, M. (2008). Swahili advertising in Nairobi: Innovation and language shift. Journal of African Cultural Studies, 20(1),-3-14. https://doi.org/10.1080/13696810802159222

Nickerson, C., \& Camiciottoli, B. C. (2013). Business English as a lingua franca in advertising texts in the Arabian Gulf: Analyzing the attitudes of the Emirati community. Journal of Business and Technical Communication, 27(3),-329-352. https://doi.org/10.1177/1050651913479930

Petrof, J. (1990). L'utilisation des langues étrangères comme moyen d'augmenter l'efficacité de la publicité: Une approche expérimentale (Using foreign languages as a Means to increase advertising effectiveness: An experimental approach). Recherche et Applications en Marketing (Marketing Research and Applications), 5, 1-16. https://doi.org/10.1177/076737019000500201

Reinares-Lara, E., Martín-Santana, J. D., \& Muela-Molina, C. (2016). The effects of accent, differentiation, and stigmatization on spokesperson credibility in radio advertising. Journal of Global Marketing, 29(1),-15-28. https://doi.org/10.1080/08911762.2015.1119919

Rodero, E. (2019). Do Your Ads Talk Too Fast To Your Audio Audience? How Speech Rates of Audio Commercials Influence Cognitive and Physiological Outcomes. Journal of Advertising Research, 60(3), 337-349. https://doi-org.sdl.idm.oclc.org/10.2501/JAR2019-038

Rodero, E., Larrea, O., \& Vázquez, M. (2013). Male and Female Voices in Commercials: Analysis of Effectiveness, Adequacy for the Product, Attention and Recall. Sex Roles, 68, 349-362. DOI 10.1007/s11199-012-0247-y

Rodero, E., Potter, R. F., \& Prieto, P. (2017). Pitch Range Variations Improve Cognitive Processing of Audio Messages. Human Communication Research, 43(3), 397-413. https://doi-org.sdl.idm.oclc.org/10.1111/hcre.12109

Sobh, R., Singh, N., Chun, W., \& Benmamoun, M. (2018). Localizing to Arabic consumers: Insights from print advertising. Journal of Marketing Communications, 24(2),-190-211. https://doi.org/10.1080/13527266.2015.1062794

Yang, H. C., Ahn, H. K., \& Han, S. H. (2013). Effects of Advertising depending upon type of Advertising and form of advertising model. The Journal of Distribution Science, 11(11), 77-82. https://doi.org/10.13106/jds.2013.vol11.no11.77. 